The American Pediatric Society and the Society for Pediatric Research announce additions to the 1985 meeting agenda.

1) POSTER PRESENTATIONS

\title{
3 LARGE POSTER SESSIONS
}

(Not in Competition with Platform Sessions)

EXHIBIT HALI B

Times: Monday, May 6, 1985: 6:00 - 9:00 p.m.

Tuesday, May 7, 1985: 6:00-9:00 p.m.

Thursday, May 9, 1985: 10:00 a.m. - 1:00 p.m.

Authors from all subspecialty areas will be in attendance at each poster session. Refreshments will be available during these sessions.

(The APS and SPR recognize the contributions of Gerber Baby Products, Co. in support of these poster sessions)

\section{2) POSTER SYMPOSIA}

In addition to poster sessions, two poster symposia will be held. In this new format, 15 posters will be available for viewing, preceding a one hour discussion led by moderators.

Subjects for this year:

CEREBRAL BLOOD FLOW

Moderators: M. Douglas Jones, Jr. and Joseph Volpe

LUNG DEVELOPMENT

Moderators: Alan Jobe and Joseph Warshaw

Listings of time, location and included abstracts for these symposia are found on pages $24 \mathrm{~A}-\mathrm{ff}$.

3) NICHD

Dr. Doris Merritt and staff from the NICHD will be available during the Thursday morning poster session in Exhibit Hall B to provide information and materials related to NIH research funding. 